\title{
Tumor/Lesion Identification Supplemental Qualifiers Dataset
}

National Cancer Institute

\section{Source}

National Cancer Institute. Tumor/Lesion Identification Supplemental Qualifiers Dataset. NCI Thesaurus. Code C147264.

A dataset containing supplemental information, specifically non-standard variables, to parent records in the tumor/lesion identification domain. 